\title{
Designing a virtual cockpit for helicopter offshore operations
}

Ernst, Johannes, Schmerwitz, Sven, Lueken, Thomas, Ebrecht, Lars

Johannes M. Ernst, Sven Schmerwitz, Thomas Lueken, Lars Ebrecht, "Designing a virtual cockpit for helicopter offshore operations," Proc. SPIE 10197, Degraded Environments: Sensing, Processing, and Display 2017, $101970 Z$ (5 May 2017); doi: 10.1117/12.2262482

SPIE. Event: SPIE Defense + Security, 2017, Anaheim, California, United States 


\title{
Designing a virtual cockpit for helicopter offshore operations
}

\author{
Johannes M. Ernst*, Sven Schmerwitz, Thomas Lueken, and Lars Ebrecht \\ Institute of Flight Guidance, \\ German Aerospace Center (DLR), Braunschweig, Germany
}

\begin{abstract}
In recent years the number of offshore wind farms is rapidly increasing. Especially coastal European countries are building numerous offshore wind turbines in the Baltic, the North, and the Irish Sea. During both construction and operation of these wind farms, many specially-equipped helicopters are on duty. Due to their flexibility, their hover capability, and their higher speed compared to ships, these aircraft perform important tasks like helicopter emergency medical services (HEMS) as well as passenger and freight transfer flights. The missions often include specific challenges like platform landings or hoist operations to drop off workers onto wind turbines. However, adverse weather conditions frequently limit helicopter offshore operations. In such scenarios, the application of aircraft-mounted sensors and obstacle databases together with helmet-mounted displays (HMD) seems to offer great potential to improve the operational capabilities of the helicopters used. By displaying environmental information in a visual conformal manner, these systems mitigate the loss of visual reference to the surroundings. This helps the pilots to maintain proper situational awareness. This paper analyzes the specific challenges of helicopter offshore operations in wind parks by means of an online survey and a structured interview with pilots and operators. Further, the work presents how our previously introduced concept of an HMD-based virtual flight deck could enhance helicopter offshore missions. The advantages of this system - for instance its "see-through the airframe"-capability and its highly-flexible cockpit setup - enable us to design entirely novel pilot assistance systems. The gained knowledge will be used to develop a virtual cockpit that is tailor-made for helicopter offshore maneuvers.
\end{abstract}

Keywords: Virtual Cockpit, Avionics, Helmet-Mounted Display, Head-Worn Display, Virtual Reality, Degraded Visual Environment, External Vision, Pilot Assistance

\section{INTRODUCTION}

Helicopter offshore operations (HOFO) are defined as "operations which routinely have a substantial proportion of the flight conducted over sea areas to or from offshore locations". ${ }^{1}$ The term 'offshore location' includes, but is not limited to: helidecks, shipboard heliports, and winching areas on vessels or renewable-energy installations. ${ }^{2}$ These operations are usually conducted for the purpose of: "(a) support of offshore oil, gas and mineral exploration, production, storage and transport; (b) support to offshore wind turbines and other renewable-energy sources; or (c) support to ships including sea pilot transfer." ${ }^{2}$

Offshore flights for the oil \& gas industry have been conducted for over 50 years. They focus on crew changes on offshore installations and provide the required emergency medical services for offshore workers. By contrast, the offshore wind energy sector is a relatively new and fast growing business. In that industry as well, helicopters are an important means for passenger transport and medical services. Compared to the oil \& gas sector, helicopter operations in wind farms pose several specific challenges for pilots, for instance hoist maneuvers at wind turbines.

The project Development of powerful and efficient Avionic-Platforms for Fixed and Rotary Wing (AVATAR) addresses these issues by developing powerful and efficient avionic-platforms for next generation cockpit display systems. AVATAR is a national joint research project funded by the Federal Ministry of Economics and Technology based on a decision by the German Bundestag. The project has four main objectives. The first is the optimization of development processes in order to reduce costs and time using family concepts, generic platforms and modelbased development methods. The second objective represents the exemplified implementation of two systems: a flight control system and a cockpit display system. The third goal is the evaluation of different display technologies

\footnotetext{
* johannes.ernst@dlr.de
} 
based on challenging helicopter operations using safety critical and processed data. Finally, the fourth purpose considers the presentation of communalities concerning fixed and rotary wing applications. In AVATAR, the German Aerospace Center (DLR) simulates sensor data using the Flexible Sensor Simulation Suite (F3S) ${ }^{3}$ and implements a fusion of sensor data with georeferenced data from an industrial database management platform. Consecutively, DLR is going to implement and evaluate enhanced and visual conformal display systems for offshore rotary wing aircraft. Referring to this the main subject is the investigation and demonstration of future cockpit display capabilities using industrial components like the JedEye ${ }^{\mathrm{TM}}$ helmet-mounted display system by Elbit Systems Ltd. as well as graphics and video controllers developed by Diehl Aerospace. At the end of the project, DLR is going to conduct a simulator study in order to evaluate and demonstrate the results.

At the current stage, our work focuses on the following main questions: What is the status quo regarding helicopter offshore operations in general and in the German offshore wind industry in particular? What are challenges and problems during day-to-day missions? Could our concept of a virtual cockpit environment based on HMD-technology be a suitable means to mitigate existing problems? To answer these questions, we collected data from several parties involved in this business. Further, we conducted an online survey and a structured interview with selected offshore pilots and operators.

The paper is structured as follows: Section 2 gives an overview of the status quo of helicopter offshore operations in general. Subsequently in Section 3, we present the results of our analysis of operational challenges for helicopters in the offshore wind industry. This is followed by a discussion on how our virtual flight deck approach could potentially tackle existing HOFO issues (Section 4). Finally, Section 5 provides a summary, draws conclusions and gives an outlook on future work.

\section{THE STATUS QUO OF HELICOPTER OFFSHORE OPERATIONS}

Helicopters have been used offshore in various regions around the world for more than 50 years. Most of the global offshore helicopter fleet is operated by the oil \& gas industry. In this chapter, we will briefly present the status quo of these activities and provide a short introduction to the European regulatory framework regarding HOFO. In Section 3, we will identify differences and similarities to helicopter operations in the evolving offshore wind industry.

\subsection{Worldwide Helicopter Offshore Operations in the Oil \& Gas Industry}

Since the oil \& gas industry began to build drilling platforms in deep waters off the coast, rotorcraft have been used during both construction and operation of these facilities. Major companies like CHC Helicopter or Bristow operate a global fleet of more than two hundred helicopters each. ${ }^{4,5}$ They conduct mainly passenger and freight transport to and from offshore installations. Further, many operators are contracted for helicopter emergency medical service (HEMS) and search and rescue (SAR) services in several offshore basins around the world. Accounting for about $42 \%$ of the hours flown worldwide, the Gulf of Mexico is the biggest offshore operation area. ${ }^{6}$ The North Sea makes up approximately $12 \%$ while the remainder is split between many regions, for example Australia, Canada, or the Middle East. In Germany, no oil \& gas helicopter operator exists.

Depending on the mission profile, operators use a wide range of helicopter types including single and twin engine aircraft. The latter can be divided further into light (up to 9 passengers), medium (up to 13 passengers), and heavy twins. ${ }^{7}$ Due to their higher capacity, longer range and higher speed, larger helicopters fly offshore workers to farther drilling fields whereas smaller aircraft often operate nearer to the coast. ${ }^{5,8}$ According to the International Association of Oil \& Gas Producers (IOGP),${ }^{9}$ the majority of helicopters flying in the Gulf of Mexico is small, twin- or single-engined and steered by only one pilot. By contrast, in Europe only twin-engined aircraft are operated offshore.

UK's Civil Aviation Authority (CAA) counted 230 offshore helicopters flying for the oil \& gas industry over the North Sea in $2014 .{ }^{10} 70 \%$ of these were based in the UK or in Norway. The majority of helicopters in both countries are heavy twins (S-92, EC225, AS332, AW189), complemented by a smaller number of medium twins like S-76, AS365, EC155, AW139 used for shorter flights. ${ }^{8}$ Light twins and single-engined aircraft are not operated in the UK and Norwegian oil \& gas industry. Over 7.8 million flights carrying more than 65.5 million passengers 
were conducted in the UK between 1976 and $2015 .{ }^{8}$ According to CAA's CAP1145 report, ${ }^{10}$ approximately 328 fixed and 70-140 mobile helidecks were in place in the UK and Norway by 2013.

With reference to a five-year-average of fewer than 0.6 fatal accidents per 100000 flying hours, ${ }^{8}$ the safety level in the UK North Sea region can be assessed as rather high. Owing to constant effort by all stakeholders, high standards have been established and the safety level has been strongly improved compared to the early years. Detailed statistics can be found in several safety studies, which are published regularly by national agencies in the UK ${ }^{10,11}$ and Norway ${ }^{12}$ as well as by industry associations like Oil $\mathscr{G}$ Gas UK. ${ }^{8,13}$ Worldwide statistics were published annually between 1998 and 2007 by the IOGP. ${ }^{7,9}$ Later, helicopter safety performance was included into IOGP's general offshore safety reports. ${ }^{14}$

Many statistics are restricted to certain regions and periods of time. Moreover, many reports are hard to compare because they use deviating definitions and collect different types of data. Thus, Nascimento et al. ${ }^{6}$ generated a database of worldwide accidents between 1997 and 2011 so as to conduct a thorough multivariate analysis. The authors count 189 accidents during that 15-year period and conclude that the overall accident rate in the North Sea (NS) was significantly lower than in the Gulf of Mexico (GOM). Further, significantly more fatal accidents were recorded in all other regions than NS and GOM. Concerning worldwide accident causes, the authors observed more operational (e.g. pilot-related or weather) than technical (e.g. airworthiness or maintenance) failures. The former occurred more frequently during approach, landing, and ground operations while the latter were spread over the cruise phase. Statistically, controlled flight into terrain or water (CFITW) claimed most lives per accident.

The work of Nascimento et al. ${ }^{6}$ confirmed previous studies as it discovered that the night-time accident rates were significantly higher. Beyond that, more deadly crashes and more fatalities per accident were recorded during the hours of darkness. These tendencies are particularly strong in regions other than NS and GOM. The percentage of night-time operations is about $3 \%$ worldwide and $8.46 \%$ in the North Sea ${ }^{6}$ Finally, the authors provide important insights into the use of medium-sized, twin-engine helicopters. Firstly, these types frequently crashed at night, which may indicate an excess of operational and human limits under these conditions. Secondly, the crash behavior and the seaworthiness of this helicopter class are questioned since - despite the lower number of passengers - as many fatalities per accident as in heavy twin crashes are recorded.

\subsection{European Regulatory Framework}

The European Union Commission Regulation (EU) No 965/2012 lays down "technical requirements and administrative procedures related to air operations". ${ }^{1}$ Annex V of this document deals with "Specific Approvals (SPA)" and includes subparts about "Helicopter Hoist Operations (HHO)" and "Helicopter Emergency Medical Service Operations (HEMS)". In 2016, the regulation was amended by Commission Regulation (EU) 2016/1199, which introduced several rules for helicopter offshore operations. ${ }^{15}$ Among other changes, a new subpart "Helicopter Offshore Operations (HOFO)" was added to Annex V. Further, the European Aviation Safety Agency (EASA) published Acceptable Means of Compliance (AMC) and Guidance Material (GM) to support the interpretation and implementation of the new rules. ${ }^{16}$

\section{OPERATIONAL CHALLENGES IN THE OFFSHORE WIND INDUSTRY}

The aim of this work is to assess the current situation of helicopter operators offering services for the offshore wind industry in the North Sea. Specifics of offshore flying shall be determined and scenarios where pilot assistance systems can help shall be identified. The following section presents our results.

\subsection{Method}

To assess the status quo, we collected data from several parties involved in the German offshore wind industry. Further, we conducted two online surveys. One was addressed to company representatives of two German helicopter operators. The other queried 14 pilots of the same two companies. Finally, we conducted a face-to-face, structured interview with three pilots of one company. After a set of general questions related to offshore flying, the subjects were asked to describe the procedures they follow during various missions and maneuvers. Moreover, we discussed frequently occurring problems and particular challenges. 


\subsection{Results}

The questioned companies offer several helicopter services including passenger and freight transport to offshore installations, offshore HEMS, sea pilot transfer, and ambulance flights. During all missions the crews perform certain demanding maneuvers: platform landings and takeoffs, various types of hoist maneuvers, and ship landings and takeoffs. The following presentation of our results is grouped into general issues, which apply to all offshore operations, and mission-/maneuver-specific characteristics.

\subsubsection{General issues}

Helicopters and equipment All German offshore helicopter service providers known to us operate light and medium twin-engine aircraft, for instance Airbus H135/H145/H155/AS365, Sikorsky S-76, or Leonardo AW139. Subject to their intended use, the helicopters are fitted with medical equipment for HEMS missions or have their cabin configured for passenger transport. Common flight times range between $30 \mathrm{~min}$ and $2 \mathrm{~h}$ depending on mission type and destination. Helicopters are equipped and certified for IFR-operations even though they usually fly under visual flight rules (VFR). Many cockpits are dominated by mechanical gages, retro-fitted with additional modern avionic systems like moving map displays. Only recently purchased aircraft are equipped with modern glass cockpits. Figure 1 provides an overview of equipment installed by the consulted operators, which had a combined fleet size of 12 helicopters. All aircraft are equipped with radar altimeter and weather radar. The majority is additionally fitted with traffic advisory system (TCAS I/II, FLARM), flight management system (FMS), and full authority digital engine control (FADEC). Fewer have digital map displays, helicopter terrain awareness and warning systems (HTAWS), and 4-axis automatic flight control systems (AFCS). Neither synthetic vision systems (SVS) nor head-worn displays (NVG, HMD) or enhanced vision sensors (radar, lidar, infrared) are installed on the helicopters in question. Further, no ship tracking systems are available.

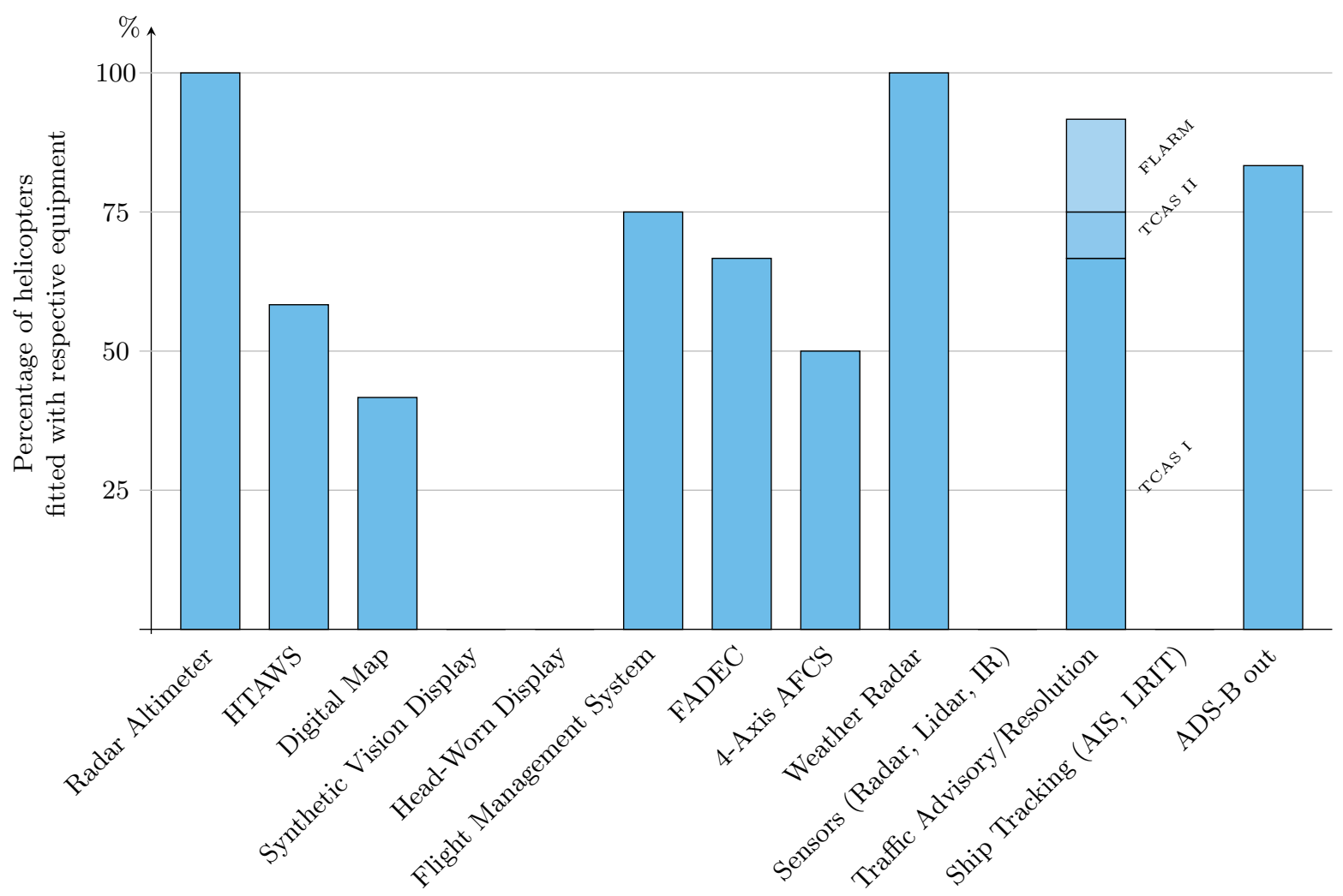

Figure 1: Overview of equipment installed in the helicopters of the consulted operators. Data expressed as percentage of the two operator's combined fleet. 
Crew Most surveyed pilots have more than 2000 flight hours experience. Often, they worked in the offshore oil \& gas industry or gained flight experience in the military before. All subjects hold instrument ratings and have flown aircraft with glass cockpits. Several pilots reported previous experience with military-grade night vision goggles (9 out of 14) and binocular helmet-mounted displays (3/14). However, synthetic vision systems have only been used by two pilots occasionally and enhanced vision systems have not been used at all. Offshore flights are always operated by two pilots. Depending on the type of mission, the crew is complemented by one hoist operator and a medical team of two. To get qualified for conducting hoist operations and landings on platforms and ships, all crew members have to complete regular training programs and checks.

Offshore flying Helicopters over the German Bight usually operate in class G airspace under VFR. However, as only few landmarks for navigation and few outside visual cues for orientation exist over the sea, the execution of the flights in practice heavily relies on cockpit instruments and satellite-based navigation. The sea often looks like a flat, mirror-like surface that offers no features for orientation or gives even wrong cues because of its moving waves. Another issue that hinders the pilots' orientation is the fact that the horizon is rarely clearly visible as water and sky often become blurred. Moreover, the North Sea is known for fierce weather phenomena which often cause degraded visibility. Then, the pilots' out-the-window view is limited by heavy precipitation, fog, clouds, or glare. These issues additionally complicate correct determination of attitude and position as well as obstacle avoidance. From a technical point of view, strong winds up to 60 knots (including gusts) are not considered to be problematic as long as maneuvers like hovering or landing can be performed with headwind. Nevertheless, turbulence can greatly complicate landing and hover maneuvers. Possible causes for turbulence are the wind turbine structure or installations on a platform or ship.

Night-time operations The darkness during night-time flights drastically increases the complexity of the missions. The general offshore issues mentioned above combined with the lack of light sources pose a great challenge to the pilots. Therefore, the interviewed operator conducts transport flights only to helidecks in specially approved wind parks. Operations at wind turbines are not performed during night-time. By contrast, inevitable HEMS missions are flown 24/7 with around $30 \%$ of the flights happening at night. The interviewed pilots stated that especially range estimation becomes very difficult, which is why they heavily rely on GPS measurements to determine their distance to the target. Often the helideck is the only illuminated reference point in the outside view. The interviewed pilots stated that night vision goggles (NVG) do not offer advantages in such a scenario.

\subsubsection{Mission and maneuver specifics}

The pilots involved in our surveys fly passengers to offshore installations, perform 24/7 offshore HEMS operations, transfer sea pilots onto ships in the German Bight, and conduct ambulance flights to several island in the North Sea. Passenger transport flights include the classic replacement of workers during shift change on an offshore platform but also the transfer of technicians onto wind turbines, ships et cetera. All mission types usually end with a landing or hoist maneuver. Most landings are performed on platform helidecks, fewer on ships. The hoist is basically used if it is impossible, inconvenient or unsafe to land; for instance if technicians are brought onto wind turbines or persons must be rescued from open water. Further, hoisting is the preferred way of transferring sea pilots or medical crew onto ships and vessels. In general, the en-route flight to the scene is described as noncritical while the mission task itself is seen as the most critical part of the operation, irrespective of whether they hoist or land. Transport missions are planned flights in known environment. Information about helidecks and hoist areas is available via the electronic flight bag (EFB) and the ground crew is specially briefed. In contrast, HEMS missions are unplanned and require experienced and specially trained pilots. Note that as civil operators the questioned are not responsible for SAR missions in Germany.

Platform landing The interviewed pilots explained that they manually fly the final approach from an imaginary gate about $0.75 \mathrm{NM}$ out to an imaginary landing decision point. The latter is located a few feet above and laterally offset to the helideck to avoid a potential collision in case of an engine failure. From there, they land sideways. The approach and landing is always conducted by the pilot sitting on the side of the helideck because the landing spot is hardly visible from the other seat. If at all possible, the whole maneuver is flown with headwind. At 


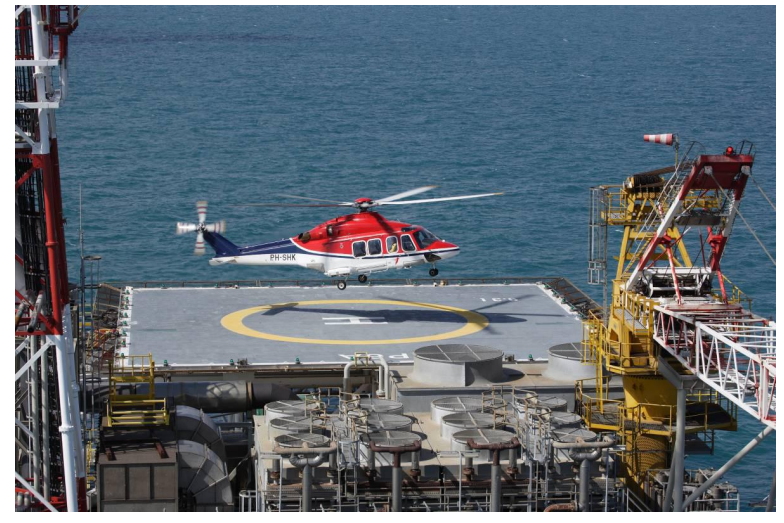

(a) Augusta Westland AW139 landing on offshore helideck surrounded by various obstacles. [Photo courtesy of CHC Helicopter]

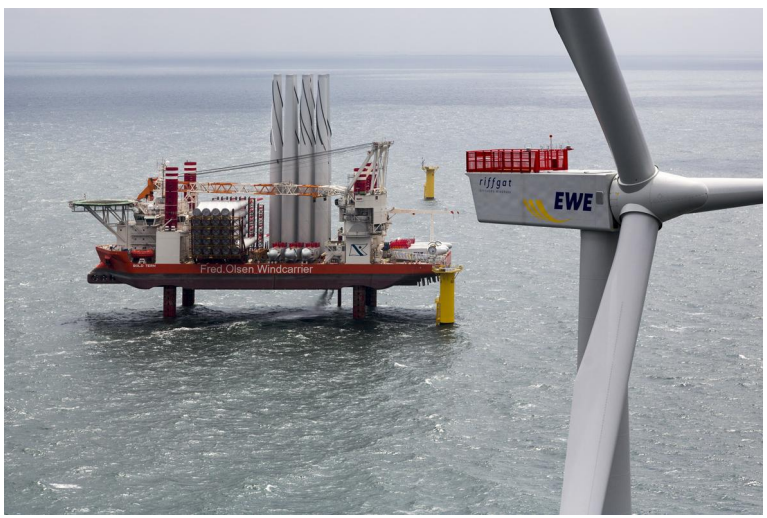

(b) Helihoist platform on top of a wind turbine nacelle and installation ship/platform with helideck on the left side. [Siemens Press Picture*. Image used with permission]

Figure 2: Examples of offshore locations where helicopters usually operate.

several platforms a helicopter approach path indicator (HAPI) guides the pilots along the correct approach path. This system is mandatory for offshore helidecks to receive night-operation approval. The high pitch during the deceleration phase restricts the pilots view of the desired landing spot. As can be seen in Figure 2a, the helideck is often surrounded by various installations, which increase the risk of a collision. Additionally, as the approach direction is predetermined by the headwind requirement, such obstacles can complicate the landing procedure and lead to side- or backwards maneuvering before touchdown.

Ship landing The procedure for ship landings is generally similar to platform approaches. However, a few advantages and drawbacks exist. On the positive side, the ship can often be instructed to maneuver such that the helicopter can optimally land against the wind and without turbulences caused by ship structures. On the negative side, the ship moves with the waves, which poses a great challenge for the pilots to perform a safe touch down. They must ignore the ship movements to keep the aircraft stable while waiting for the right moment to land when the ship is in a suitable attitude for a few seconds.

Hoist operations Offshore hoist maneuvers can be distinguished according to the environment. In many cases persons are winched from or onto predefined hoist areas on ships, platforms, or wind turbines. However, in HEMS scenarios the hoist is used wherever necessary, for example to rescue persons from the sea. Since the pilots are not able to see the person to be picked up or set down under the helicopter, the hoist operator plays an important role. The pilots keep the aircraft in a stable hover while the hoist operator acquires visual contact with the person and directs the cockpit crew by voice commands. Especially with moving targets like ships or persons in the sea, this procedure can be cumbersome and requires special training and good crew coordination. Airlifting to wind turbines can either be performed at a heli-hoist platform on top of the nacelle (Figure 2b) or at an access platform at the bottom of the wind turbine tower. Our interview partners indicated that during the latter they have problems maintaining separation between helicopter and tower. The reason for this is that the white tower appears like a large, texture-less surface making it extremely difficult to estimate the distance without auxiliary devices. The workload of the crew could be reduced by an AFCS with automatic hover functionality. However, the helicopters in question are not equipped with this technology.

\footnotetext{
${ }^{*}$ www.siemens.com/presspictures
} 


\subsection{Discussion}

Our results show that helicopter operations at German offshore wind farms are highly demanding for crew and equipment. Additionally, the work reveals that certain procedures definitely leave room for improvement. For the discussion it must be kept in mind that our results are based on information from two German offshore helicopter operators and may not be fully representative of all involved companies. Moreover, certain mission profiles like SAR are not covered.

We found many similarities but also differences between helicopter operations in wind farms and in the established oil \& gas industry. On the one hand, rotorcraft operators in both domains provide similar services, mainly transport flights and HEMS. Further, both operate in the same harsh and challenging environment leading to similar requirements for crew and equipment. On the other hand, hoist operations at wind turbines play an important role for the surveyed operators while the oil \& gas industry is more focused on scheduled passenger transport to and from offshore helidecks. Furthermore, oil \& gas helicopter services rely on heavier aircraft with higher passenger capacity and longer range because many drilling rigs are farther offshore and employ more workers than current wind farms in Germany. For operations near wind turbines, smaller helicopter dimensions are advantageous. However, the capacity and range requirements could change as the wind energy sector grows further. Another difference is that the German wind industry and the associated helicopter service providers are small compared to their counterparts in the worldwide oil \& gas sector. They operate fewer than ten aircraft per company whereas the biggest oil \& gas companies own a worldwide fleet of several hundred helicopters.

Even though they mostly operate under VFR, all pilots and aircraft are IFR-certified to be prepared best for the special offshore environment and for highly demanding mission profiles like night air rescue. The helicopters are (retro-)fitted with various technology like weather radar, digital map displays, or AFCS, which makes offshore operations safer. However - due to budget constraints - not all latest technical advancements are installed and the transition to newer aircraft happens rather slow. For instance, none of the helicopters is equipped with automatic hover functionality and synthetic or enhanced vision systems. This leaves room for improvement.

Analyzing the results of the interview, we can identify two major issues appearing throughout all examined missions and maneuvers:

1. Lack of usable outside visual cues,

2. Restricted external view caused by non-transparent parts of the airframe.

Lack of usable outside visual cues Onshore pilots flying under VFR can orient themselves by looking out of the window at the horizon, various objects, and terrain features. The offshore environment, however, offers only few usable outside visual cues. Firstly, only few fixed objects exist. Secondly, usable optical flow and ground texture cues are rarely available from the water surface. Caused by its own movement, the sea often provides more misleading than valuable information. Thirdly, this shortage of external references is often even aggravated by weather conditions that further degrade the view and obscure the horizon. These issues are of great importance especially during night-time missions, while hovering over open water without fixed references in the surroundings, and when landing on ships that follow the waves. Moreover, the distance estimation problems during hover next to a white wind turbine tower arise from the absence of valuable visual cues in combination with difficulties caused by the pilots' perspective.

Restricted external view The limited sight from the pilots' seats appears to be relevant in many scenarios. Pilots are not able to see what happens below, above, and behind them. Even the forward and sideward view is severely restricted. The front windows are relatively small and the instrument panel covers a large amount of the pilots' forward view. This leads to a poor view of the landing spot during approaches with high pitch angle. Related issues are the control of separation from obstacles located at non-observable places and the missing direct view of persons being hoisted. These problems can partly be mitigated if a hoist operator is aboard. They can keep their eyes out and instruct the pilots. However, the multi-stage process from the hoist operator's information perception to the pilot's final control input is time-consuming and error-prone. Furthermore, the hoist operator's sight is also limited as they usually sit at the cabin door on the right-hand side of the helicopter. 
Our research will address these issues by developing new pilot assistance systems tailor-made for offshore missions. Modern enhanced and synthetic vision systems (EVS, SVS) as well as head-/helmet-mounted displays (HMDs) are expected to support pilots in such situations as they already proved in other degraded visual environment (DVE) scenarios. ${ }^{17-19}$ For instance, HMDs can generate virtual, world-referenced objects giving the pilots valuable cues for their orientation judgment. According to the interviewed pilots, even a simple horizon visualization is expected to improve their situation awareness. More advanced, visual conformal symbology could help them to better control helicopter attitude and drift or to follow the intended flight path in DVE. The demanding mission profiles and the long daily operation hours place high requirements on usability and comfort of the HMD.

\section{A VIRTUAL COCKPIT FOR HELICOPTER OFFSHORE OPERATIONS}

In earlier work we introduced the concept of a virtual cockpit environment based on HMD technology. ${ }^{20,21}$ This idea is related to the well-known pilot assistance systems using see-through HMDs. The main difference between these established systems and our concept is that - instead of a transparent HMD - we employ an opaque HMD for the virtual cockpit. The great advantage of such a virtual reality (VR) system is that it gives the display designer full control of what the pilot sees. However, as such a display blocks out the real environment, we need to ensure that all relevant information is shown on the head-worn VR display. This includes basically two domains: 1) the information which is usually provided by the external vision through the cockpit windows (far domain), and 2) the information presented on the cockpit instrument panel (near domain). Both types of information are now displayed on the VR goggles.

\subsection{The Virtual Cockpit Concept}

Figure 3 illustrates our virtual cockpit concept. The non-see-through VR headset offers a very wide field of view (FOV), a full color display, and good wearing comfort. Moreover, no external light hits the display and the pilot's eyes. This implies that display glaring, brightness issues, and other undesired interferences between display and reality, which are known from see-through HMDs, are eliminated by design. It displays the following types of information:
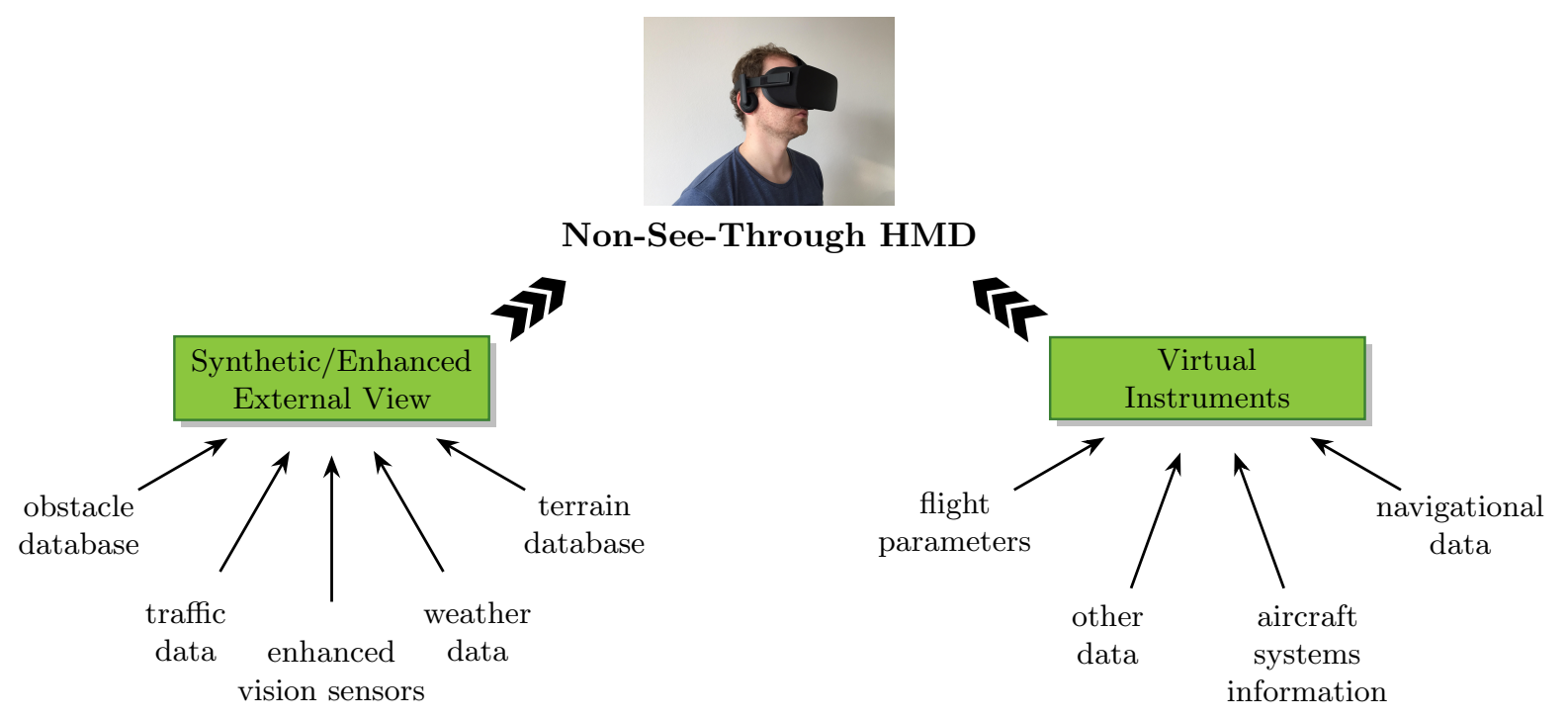

Figure 3: Basic concept of our HMD-based virtual cockpit environment.

Synthetic/Enhanced External View The external view domain provides an artificial representation of the environment that replaces the pilot's natural out-the-window view. It is comparable to enhanced, synthetic, and external vision systems (EVS, SVS, XVS) as it incorporates data from terrain and obstacle databases, from 
aircraft-mounted sensors and from various other sources (e.g. traffic, weather). Unlike vision systems using panel-mounted displays (PMDs), which are restricted to the monitor size, this external view can make use of the whole $360^{\circ}$ field of regard of a head-tracked HMD as long as human head rotation limits are respected. The system immerses the pilot in the synthetic external view.

Virtual Instruments Like the conventional cockpit instruments, our virtual instruments provide information such as flight parameters, navigation data, or aircraft systems status. However, our virtual instruments are more flexible than a state-of-the-art cockpit. They are location-independent and can take various shapes and forms, from a simple virtualization of conventional head-down instruments to a completely re-designed layout making full use of new opportunities in VR. Further, established approaches from see-through HMD display design can be transferred. For instance, visual conformal representations and scene-linked display elements can also be implemented in our virtual cockpit environment. For an in-depth explanation of the approach and its expected benefits, please refer to our previous publication. ${ }^{21}$

\subsection{Use Cases for an Offshore VR Cockpit}

Recalling the interview results presented in Section 3, we can state two major challenges for helicopter offshore operations: 1) the lack of usable outside visual cues, and 2) the restricted external view caused by non-transparent parts of the airframe. The approach taken by our virtual cockpit environment offers the potential to tackle these issues. The missing outside visual cues can be simply generated since the whole presentation of the surroundings is in the hand of the display designer. Thus, a sensor-based view can be overlaid with appropriate cueing symbology or a full synthetic view with the required cues can be displayed. The view restrictions caused by the airframe could be overcome by means of the HMD's $360^{\circ}$ field of regard. The basis for this is that the applied sensors and databases provide adequate data to generate a wide-FOV representation of the surroundings. These ideas create a lot of room for extensive research.

A first use case can be a landing maneuver on an offshore platform. Here, the "see-through the airframe"capability enables to pilots to better see the landing spot and obstacle formations during the entire approach phase. Such a system could facilitate landings from both seats of the flight deck. This would be beneficial for single pilot operations and in case of pilot incapacitation. Keeping the pilots' natural perspective, their view would still be restricted by the human head rotation limits and FOV. Thus, an even better overview could be provided by presenting other perspectives of the situation. For example, it has to be evaluated if a third person view on the HMD improves situational awareness and flight performance.

Another scenario is the application of our virtual cockpit to hoist maneuvers. Similar to the landing case, the "see-through the airframe"-capability or other display perspectives will permit the view of the person to be hoisted. Furthermore, visual references supporting a stable hover performance can be incorporated in the virtual display environment.

\section{CONCLUSIONS AND FUTURE WORK}

Helicopter offshore operations have been playing an important role for the oil \& gas industry for over 50 years. With the emerging construction of wind turbines in European waters, helicopters are also operated in offshore wind farms. We found that these new types of missions and the established oil \& gas operations share many similarities, for instance various problems caused by the harsh environment. Nevertheless, with the new wind farm operations many new challenges like hoist maneuvers at wind turbines arise. By means of an online survey and a structured interview, we identified specifics of offshore flying in general and challenges related to specific wind park missions and maneuvers. In summary, the challenges are caused by two major problems: 1) the lack of usable outside visual cues and 2) the restricted external view caused by non-transparent parts of the airframe. These issues complicate offshore HEMS and passenger transport missions and pose great challenges for the crew when conducting hoist maneuvers or landings on platforms and ships.

Our previously introduced virtual cockpit concept can tackle and potentially mitigate the identified issues. It introduces great freedom for the display design and enables us to develop entirely novel pilot assistance systems. For instance, we can realize a "see-through the airframe"-function or implement a highly-flexible cockpit setup 
that specifically adapts to the current task. The realization and evaluation of our concept idea leaves room for widespread research studies, which we will approach in our future work. As a start, we set up a flexible display design suite for various consumer-grade head-worn displays. ${ }^{22}$ Moreover, we installed a new helicopter flight simulator including professional active force feedback controls. It is capable of simulating a conventional flight deck as well as a virtual cockpit environment (Figure 4).

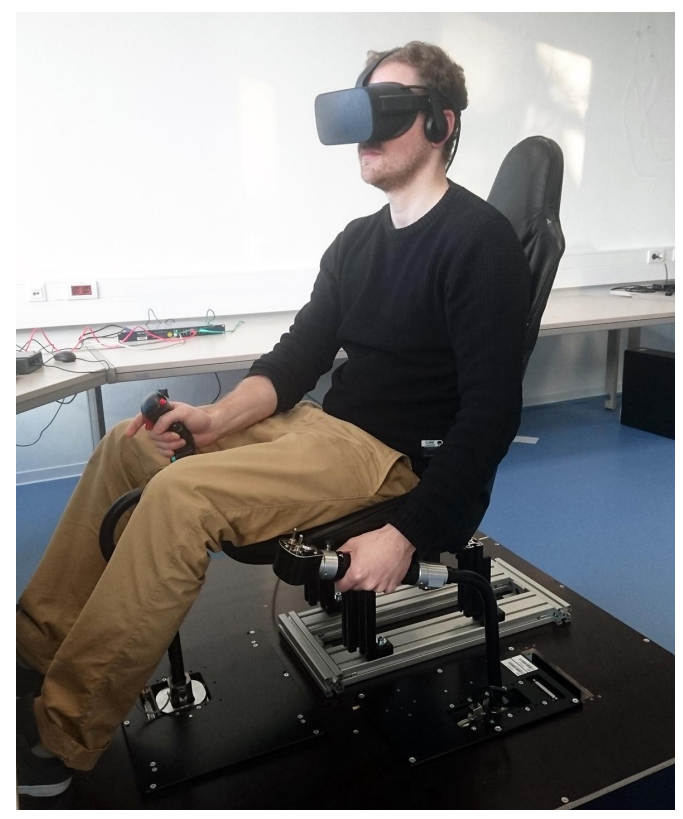

Figure 4: Testing our new VR cockpit simulator during the setup process.

\section{ACKNOWLEDGEMENTS}

The authors would like to thank all participating pilots and contributors. Special thanks go to helicopter offshore service providers and pilots participating in the study. The study was financed by the Aeronautical Research Program V (LuFo V) of the German Federal Ministry of Economic Affairs and Energy in the project AVATAR (on the basis of a decision by the German Bundestag).

\section{REFERENCES}

[1] European Commision, "Commission Regulation (EU) No 965/2012: Air operations," Official Journal of the European Union 55(L 296), 1-148 (2012).

[2] European Aviation Safety Agency, "Guidance Material (GM) to Annex I - Definitions for terms used in Annexes II to VIII of Commission Regulation (EU) 965/2012," (31.10.2016).

[3] Döhler, H.-U. and Peinecke, N., "An evaluation test bed for enhanced vision," in [Enhanced and Synthetic Vision 2010], Proc. SPIE 7689, 768907 (2010).

[4] CHC Helicopter. http://www.chcheli.com/. (Accessed: 09.03.2017).

[5] Bristow Group, "2016 Annual Report," (2016).

[6] Nascimento, F. A. C., Majumdar, A., and Ochieng, W. Y., "A 15-year multivariate analysis of worldwide offshore helicopter accidents," in [Proceedings of the 69th American Helicopter Society International Annual Forum 2013], (2013).

[7] OGP - International Association of Oil \& Gas Producers, "Safety performance of helicopter operations in the oil \& gas industry 1998," Report No. 6.83/300 (1999).

[8] Oil \& Gas UK, "Health \& Safety Report 2016," (2016).

[9] OGP - International Association of Oil \& Gas Producers, "Safety performance of helicopter operations in the oil \& gas industry 2007," Report No. 424 (2009). 
[10] Civil Aviation Authority, "Safety review of offshore public transport helicopter operations in support of the exploitation of oil and gas," CAP 1145 (2014).

[11] Civil Aviation Authority, "Safety review of offshore public transport helicopter operations in support of the exploitation of oil and gas - Progress report 2016," CAP 1386 (2016).

[12] Herrera, I. A., Habrekke, S., Krakenes, T., Hokstad, P. R., and Forseth, U., "Helicopter Safety Study 3 (HSS-3)," SINTEF A15753, SINTEF Technology and Society - Safety Research (2010).

[13] Oil \& Gas UK, "Health \& Safety Report 2015," (2015).

[14] IOGP - International Association of Oil \& Gas Producers, "Safety performance indicators - 2015 data," (2016).

[15] European Commision, "Commission Regulation (EU) 2016/1199," Official Journal of the European Union 59(L 198), 13-37 (2016).

[16] European Aviation Safety Agency, "Executive Director Decision 2016/022/R," (6.10.2016).

[17] Szoboszlay, Z. P., Fujizawa, B. T., Ott, C. R., Savage, J. C., Goodrich, S. M., McKinley, R. A., and Soukup, J. R., "3D-LZ Flight Test of 2013: Landing an EH-60L Helicopter in a Brownout Degraded Visual Environment," in [Proceedings of the 70th American Helicopter Society International Annual Forum 2014], (2014).

[18] Münsterer, T., Völschow, P., Singer, B., Strobel, M., and Kramper, P., "DVE flight test results of a sensor enhanced 3D conformal pilot support system," in [Degraded Visual Environments: Enhanced, Synthetic, and External Vision Solutions 2015], Proc. SPIE 9471, 947106 (2015).

[19] Schmerwitz, S., Lüken, T., Döhler, H.-U., Peinecke, N., Ernst, J. M., and da Silva Rosa, D., "Conformal Displays: Human Factors Analysis of Innovative Landing Aids," Optical Engineering 56(5) (2017).

[20] Lüken, T., Ernst, J. M., and Döhler, H.-U., "Virtual Cockpit Instrumentation Using Helmet Mounted Display Technology," in [Proceedings of the 41st European Rotorcraft Forum 2015], (2015).

[21] Ernst, J. M., Döhler, H.-U., and Schmerwitz, S., "A concept for a virtual flight deck shown on an HMD," in [Degraded Visual Environments: Enhanced, Synthetic, and External Vision Solutions 2016], Proc. SPIE 9839, 983909 (2016).

[22] Peinecke, N. and Ernst, J. M., "VR and AR environments for virtual cockpit enhancements," in [Degraded Environments: Sensing, Processing, and Display 2017], Proc. SPIE 10197 (2017). 